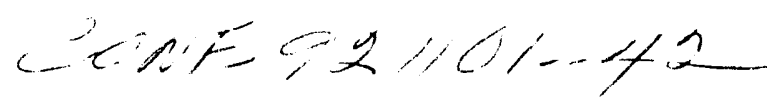

\section{CROSS-SECTIONAL TEM STUDIES OF DIGM IN IRRADIATED Au-Cu BILAYERS*}

\author{
Yuzun Gao**, Dale E. Alexander and L.E. Rehn \\ Materials Science Division \\ Argonne National Laboratory \\ Argonne, IL 60439
}

ANL/MSD/CP-76616

DE93 005552

November 1992
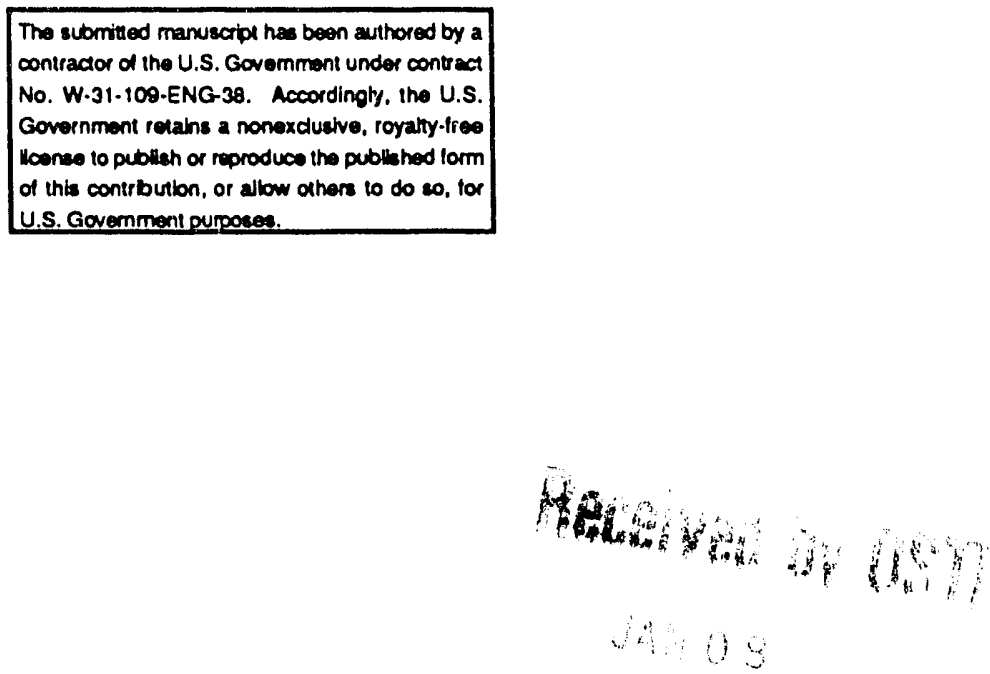

Will be presented at the Fall Meeting of the Materials Research Society: Symposium A, Boston, MA, November 30-December 4, 1992.

* Work supported by the U.S. Department of Energy, BES-Materials Sciences, under contract \#W-31-109-ENG-38.

** Visiting scholar from the General Research Institute for Non-Ferrous Metals, Beijing, PRC. 
CROSS-SECTIONAL TEM STUDIES OF DIGM IN IRRADIATED Au-Cu BILAYERS

YUZUN GAO*, DALE E. ALEXANDER and L.E. REHN

Materials Science Division, Argonne National Laboratory, Argonne, Il 60439

\section{ABSTRACT}

Cross-sectional transmission electron microscopy was used to study diffusion-induced grain boundary migration (DIGM) in irradiated and annealed $\mathrm{Au} / \mathrm{Cu}$ bilayers. Using this technique, in combination with small probe X-ray energy dispersive spectroscopy, DIGM alloyed zones in Au were identified in an irradiated sample.

\section{INTRODUCTION}

Ion-beam processing is commonly used to alter thin film microstructure through amorphization, grain growth, phase formation, etc. However, its possible consequences on diffusion-induced grain boundary migration (DIGM) have until recently received only brief and incomplete consideration [1]. DIGM is a well-characterized thermal effect in which the diffusion of a solute induces grain boundary migration in a solvent forming a substitutionally alloyed zone in the boundary's wake [2]. The process provides an efficient means of interdiffusion at relatively low temperatures and may therefore have important consequences for ion beam processing and on the fundamental interpretation of ion-solid interactions.

Experiments were undertaken to elucidate the effect of irradiation on DIGM during ion mixing of $\mathrm{Au} / \mathrm{Cu}$ bilayers $[3,4]$. Identification of DIGM in such thin-film experiments typically involves microstructural observation of boundary migration in plan-view transmission electron microscopy (TEM) combined with detection of alloyed zones in the wakes of migrated boundaries via X-ray energy dispersive spectroscopy (XEDS). However, interdiffusion of the $\mathrm{Au}$ and $\mathrm{Cu}$ caused by ion-beam mixing in irradiated bilayers obscures the view of grain boundaries, precluding this type of analysis (see Fig. 1). Because of such difficulties, Rutherford backscattering spectrometry (RBS) was used to profile the $\mathrm{Cu}$ in the $\mathrm{Au}$ film and thus measure the magnitude of DIGM in ion beam mixing experiments $[3,4]$.

Despite the success of the RBS technique, microstructural evidence of DIGM in irradiated $\mathrm{Au} / \mathrm{Cu}$ was desired. In order to overcome the limitations of plan-view TEM, the crosssection method was employed. Limited effort has been applied to examining DIGM in thin films using the cross-section TEM technique [5]. This is probably because most DIGM studies have concentrated on metallic films, which, unlike semiconductor films, are more difficult to fabricate in cross-section. This difficulty is exacerbated in samples where simultaneous thinning of a high sputtering rate metal $(\mathrm{Au})$ and a low sputtering rate ceramic substrate $(\mathrm{MgO})$ is required. Notwithstanding, the results of the work described here demonstrate, it is believed for the first time, successful use of cross-section TEM for identifying DIGM in thin metal films.

* Visiting scholar from the General Research Institute for Non-Ferrous Metals, Beijing, PRC 

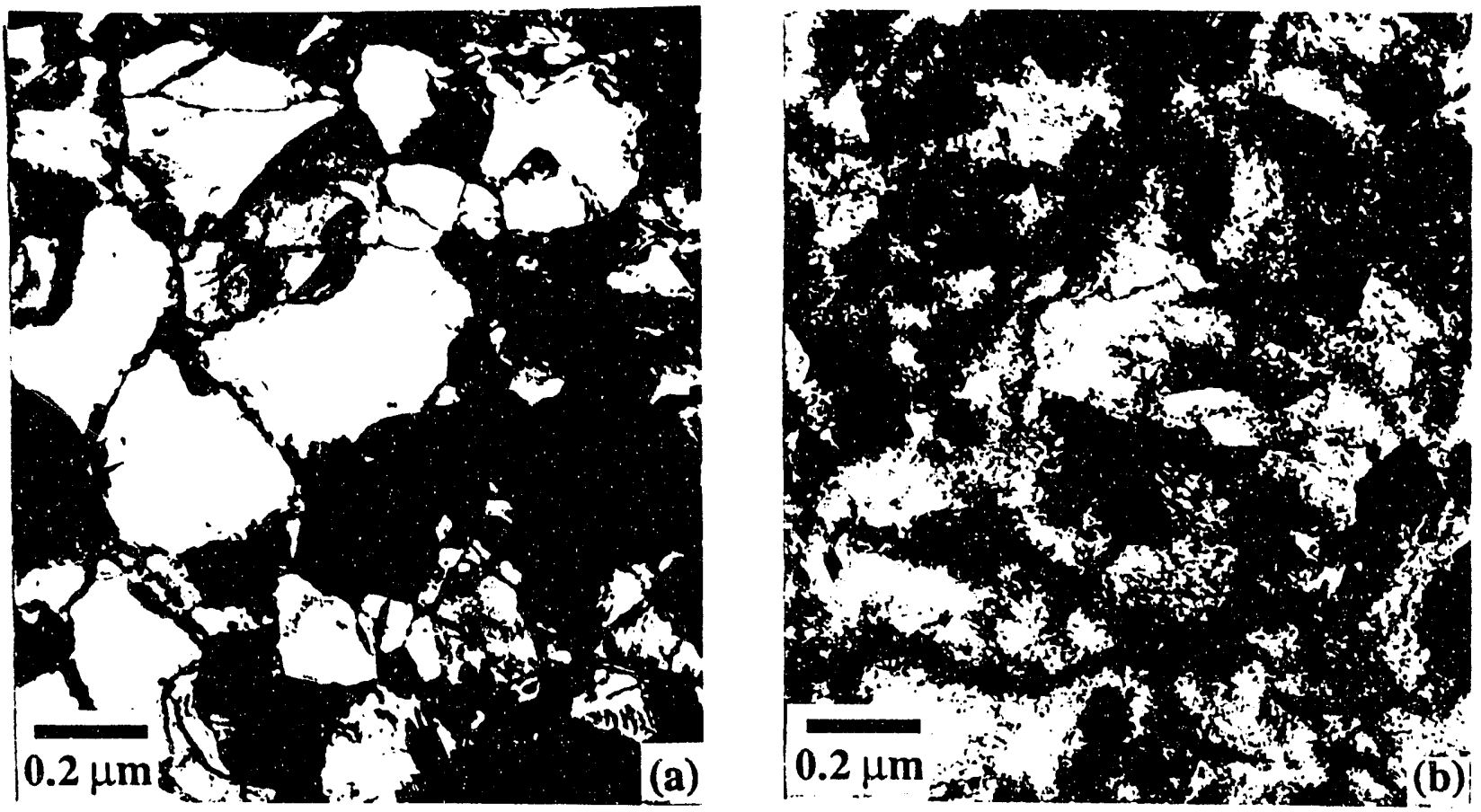

Fig. 1. Plan-view TEM images of Au films originally from $\mathrm{Au} / \mathrm{Cu}$ bilayers used in DIGM experiments. (a) film from bilayer annealed at $500 \mathrm{~K}$ for $40 \mathrm{~min}$. (b) film from bilayer irradiated at $500 \mathrm{~K}$ with $1.5 \mathrm{MeV} \mathrm{Kr}$ to $10^{15} \mathrm{~cm}^{-2}$.

\section{EXPERIMENTAL}

Bilayer preparation, irradiation and annealing treatments have been described in detail elsewhere $[3,4]$. In brief, appropriately structured polycrystalline Au films were prepared by ebeam evaporation onto (100) single-crystal $\mathrm{MgO}$ substrates ( 0.010 inches thick) in film thicknesses ranging between 340-2170 . Subsequently a $\mathrm{Cu}$ overlayer was deposited on the $\mathrm{Au}$. Portions of the bilayers were irradiated at various temperatures (300-550 K) using $1.5 \mathrm{MeV}$ $\mathrm{Kr}$ ions to doses typically about $10^{15} \mathrm{~cm}^{-2}$ at dose rates of $(0.5-1.0) \times 10^{12} \mathrm{~cm}^{-2} \mathrm{~s}^{-1}$.

Following RBS analysis, samples were prepared for cross-sectional TEM in the following manner. For a given sample treatment (as-evaporated, irradiated or annealed), two pieces of $\mathrm{MgO}(\sim 1 \times 2 \mathrm{~mm})$ containing the bilayers were cleaved from a sample. These pieces were bonded, film to film, with $\mathrm{M}$ Bond 610 Adhesive ${ }^{10}$ and subsequently baked at $363 \mathrm{~K}$ for 1 hour. The bonded pieces were then set in a $3 \mathrm{~mm}$ diameter by $1 \mathrm{~mm}$ thick stainless steel ring using epoxy or Torr-Seal ${ }^{\circledR}$. Specimens were ground to $100-150 \mu \mathrm{m}$ thickness using 10 and 3 $\mu \mathrm{m}$ SiC paper. A VCR Group dimpler, loaded to $20 \mathrm{~g}$, pre-thinned the samples to $10-15 \mu \mathrm{m}$ thickness. This proved to be a critical step; the brittleness of the $\mathrm{MgO}$ substrates made them extremely fragile during this dimpling process. Samples were then thinned to perforation in a VCR Group ion mill operated at $5.5 \mathrm{kV}$ and $0.12 \mathrm{~mA}$, with the Ar ion beam incident at $15-18^{\circ}$ to the sample surface. Ion milling typically required 10-15 hours for each sample.

Imaging and convergent beam electron diffraction (CBED) of samples were performed in a Phillips CM-30 transmission electron microscope operated at $300 \mathrm{kV}$. A Hitachi 2000 
transmission microscope with a $1 \mathrm{~d}$ emission gun, operated in analytical mode at $200 \mathrm{kV}$, was used for XEDS. Small electron-be. ... probes, approximately $20 \AA$ in diameter, were employed. The sample had to be cooled to $\mathrm{LN}_{2}$ temperature to minimize contamination during analysis. Copper composition was determined with the program NEDQNT [6] using the Cu-K $\mathrm{K}_{\alpha}$ and Au$\mathrm{L}_{\alpha}$ net peak counts (integral peak counts minus background) as input.

\section{RESULTS AND DISCUSSION}

Cross-section samples obtained from the bilayers were extremely fragile. Although ten samples were successfully prepared and imaged in TEM, only one proved resilient enough to permit a thorough small-probe XEDS analysis. The fragility of these specimens is believed due in large part to internal stresses retained in the high melting point $\mathrm{MgO}$ substrates during singlecrystal fabrication. Electron beam-induced thermal gradients often shattered the $\mathrm{MgO}$ and detached the Au films thus precluding XEDS analysis.

Fig. 2(a) shows a TEM view of a cross-section sample that was first annealed at $450 \mathrm{~K}$ for $1200 \mathrm{~s}$, then irradiated to $10^{15} \mathrm{~cm}^{-2}$ at $500 \mathrm{~K}$. As a result of DIGM, a distinct Cu alloyed zone was formed laterally and through the thickness of the Au film. The extent of this zone was delineated by a number of small probe XEDS measurements and is indicated by the hatched region in Fig. 2(b). Fig. 3 shows representative XEDS spectra obtained from the alloyed zone

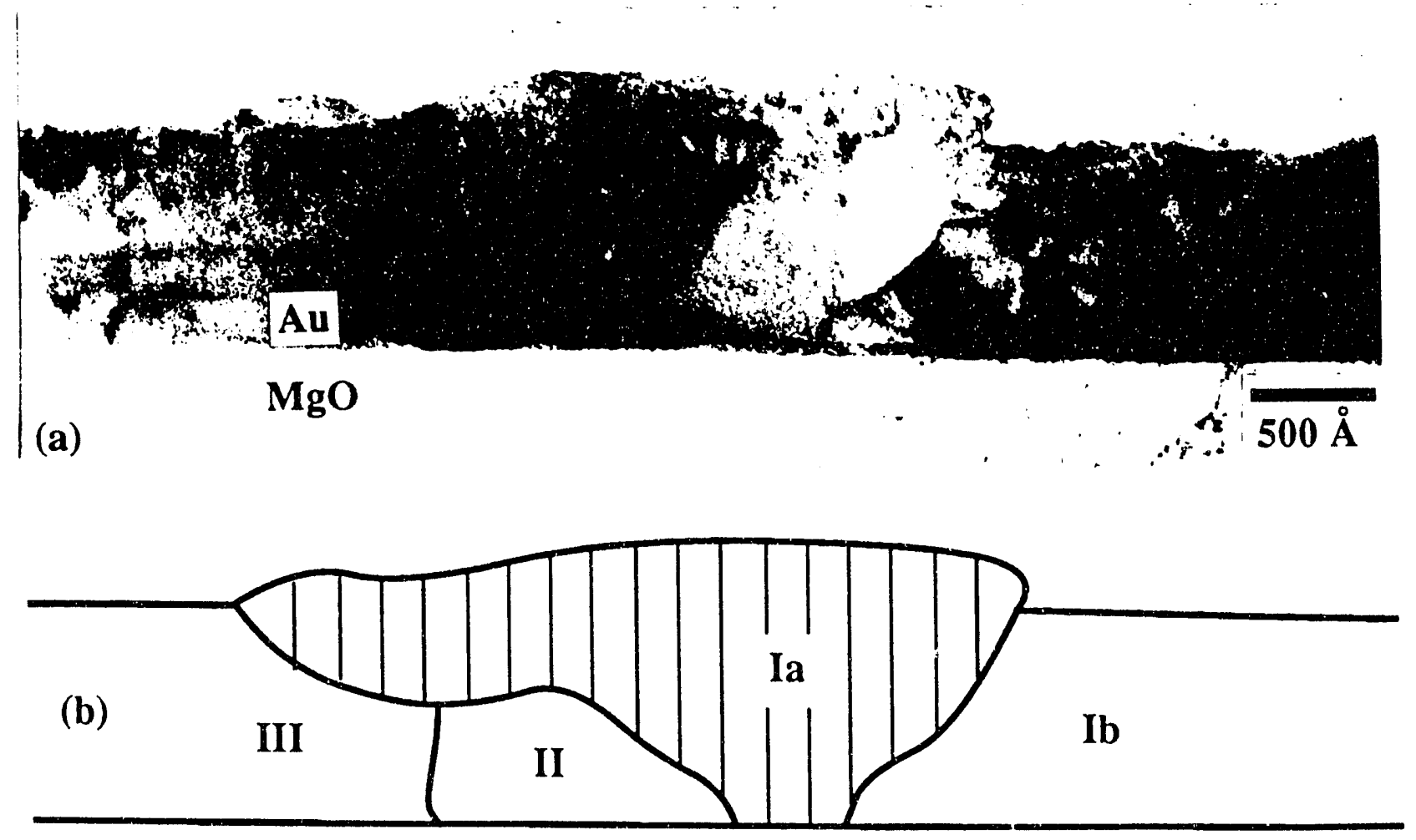

Fig. 2. (a) Cross-section TEM view of a $\mathrm{Au}$ film of an ion-beam mixed $\mathrm{Au} / \mathrm{Cu}$ bilayer containing a DIGM alloyed zone. (b) Schematic of (a) with hatched region delineating DIGM alloyed zone ( $\geq 20$ at.\% $\mathrm{Cu}$ ) as determined from small probe XEDS. Different Au grain orientations indicated by I, II and III. 


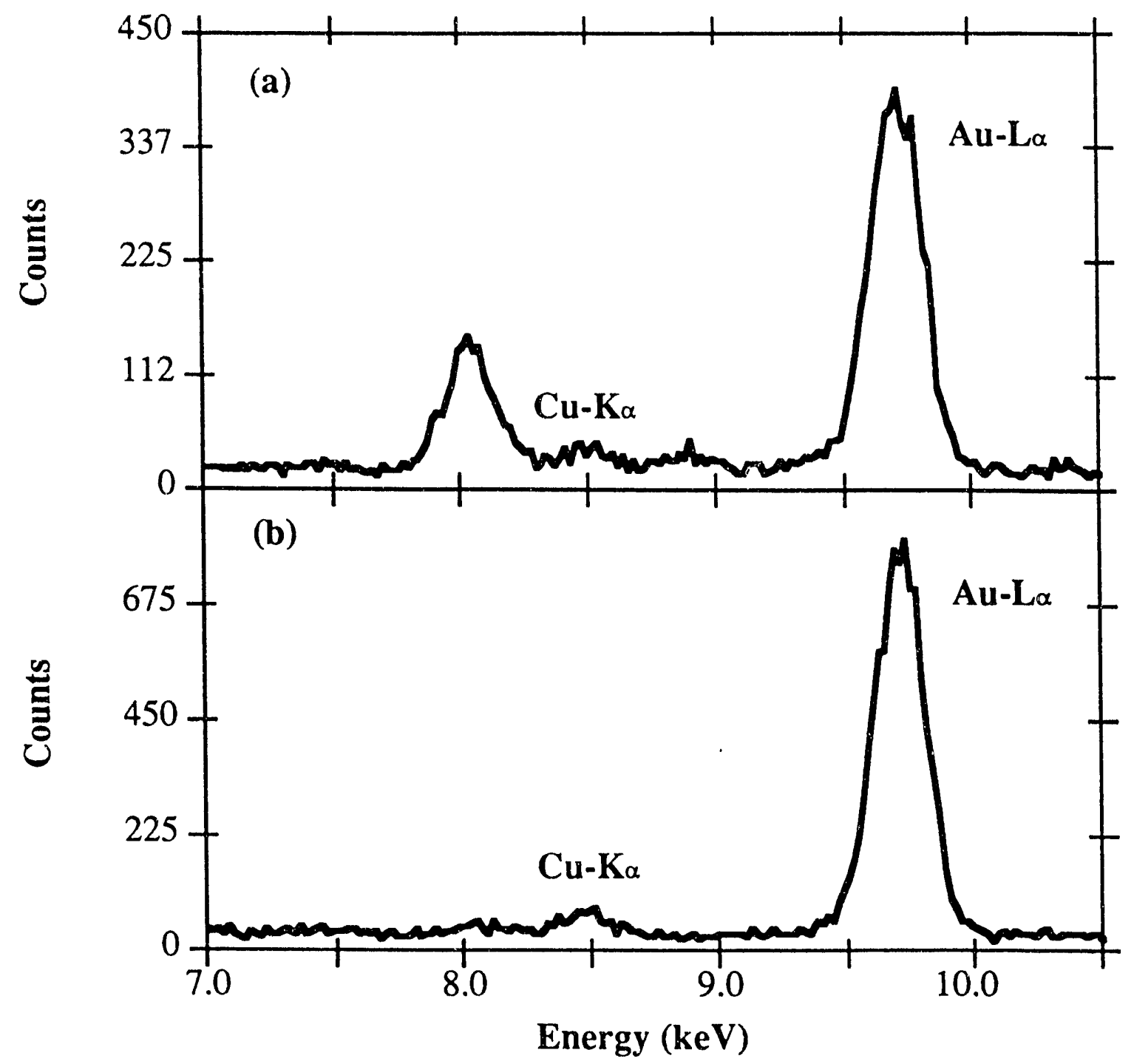

Fig. 3. Small probe XEDS spectra obtained from sample displayed in Fig. 2 showing Au and $\mathrm{Cu}$ signals used for composition analysis. (a) spectrum from alloyed zone (hatched region in Fig. 2). (b) spectrum from region adjoining alloyed zone (area II in Fig. 2).

(a) and adjacent regions (b) of the sample shown in Fig. 2. The $\mathrm{Cu}$ composition in the alloyed zone determined from Fig. 2(a) is about 20 at.\%; significantly greater than that determined from the unalloyed regions of the Au film, represented by Fig. 2(b), in which the composition was less than 4 at.\% $\mathrm{Cu}$.

Three other DIGM alloyed zones were identified in this sample similar to the one shown in Fig. 2. The average $\mathrm{Cu}$ composition measured in these other zones varied between 14-17 at.\%. These amounts are of the same magnitude as those previously measured by Pan and Balluffi (15-35 at.\% Cu) after thermal treatments [7]. They also compare favorably with those obtained from XEDS performed on irradiated plan-view samples ( 25 at. \% $\mathrm{Cu})[3]$.

Fig. 4 displays CBED patterns obtained from various locations of the film imaged in Fig. 2. It is evident from these patterns that the $\mathrm{Cu}$ alloyed zone has the same crystallographic orientation (Ia) as the adjoining low Cu region to the right in the micrograph (Ib). This is consistent with DIGM having occurred with the boundary moving from right to left. The 

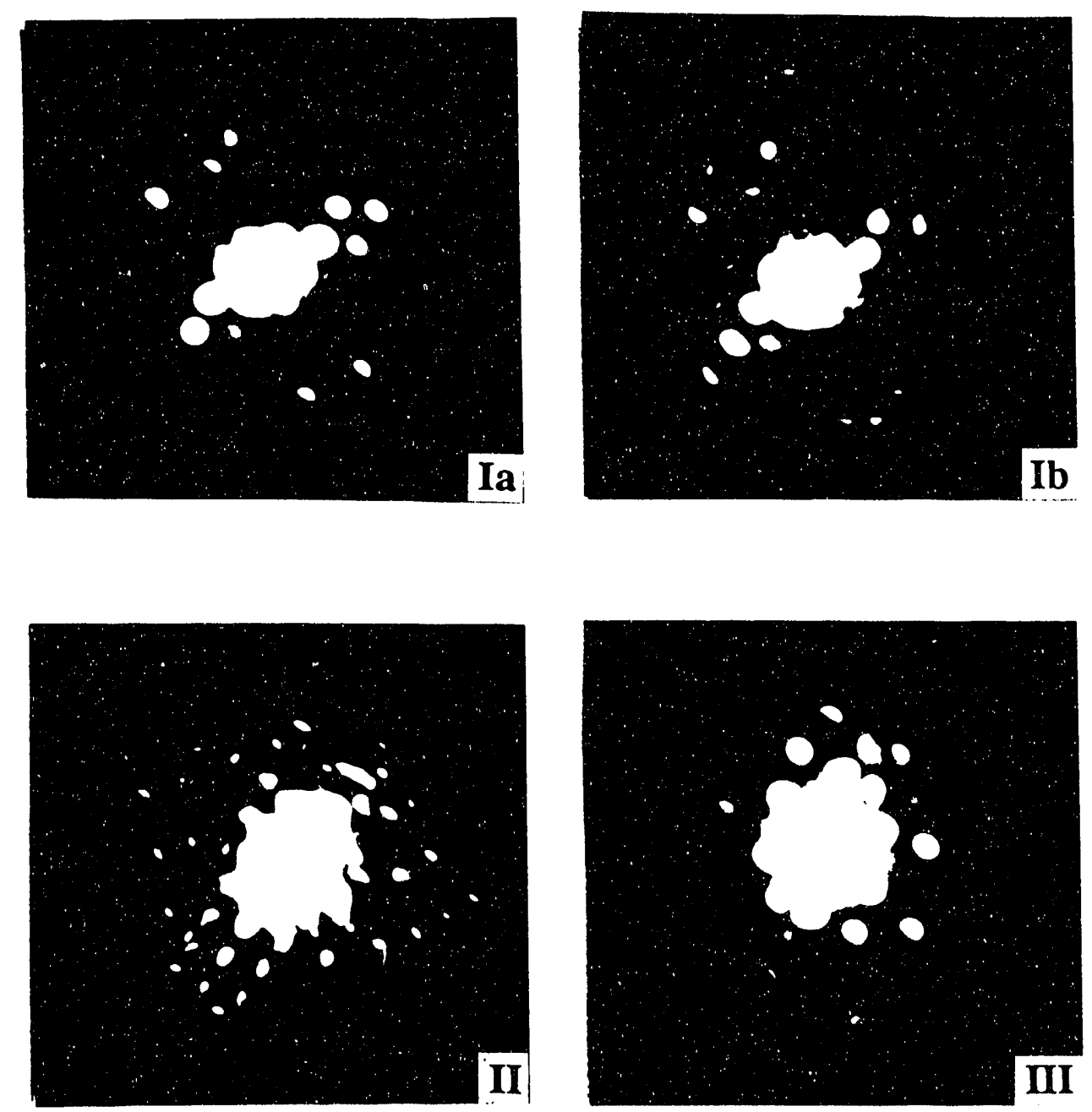

Fig. 4. CBED patterns obtained from the different locations indicated in Fig. 2.

alloyed zone is bounded on the left by low $\mathrm{Cu}$ content grains with distinctly different crystallographic orientations (II and III) as evidenced from CBED patterns in Fig. 4.

\section{CONCLUSIONS}

Direct microstructural evidence of DIGM resulting from irradiation of a $\mathrm{Au} / \mathrm{Cu}$ bilayer was obtained from a combination of XEDS and CBED performed on cross-section TEM samples. Despite difficulties in sample preparation, this work demonstrated the capability of cross-sectional TEM technique for studying DIGM in thin metal films. The fragility of samples, due to strong internal stresses in $\mathrm{MgO}$ retained from single crystal fabrication, may be lessened by using other lower melting point single-crystal substrates (e.g. sapphire) in which such stresses are lower. 


\section{ACKNOWLEDGMENTS}

The authors wish to thank H. Zhang from the Department of Materials Science and Engineering at Northwestern University for assistance in operating the Hitachi 2000 TEM. This work is funded by the U. S. Department of Energy, BES-Materials Sciences, Contract \#W-31-109-Eng38.

\section{REFERENCES}

[1] S. K. Prasad, H. Herman, A.H. King and A. Goland, in Proceedings Electron Microscopy Society of America, Fortieth Annual Meeting, edited by G.W. Bailey (Claitor's Publishing Division, San Francisco, CA, 1982), pp. 634-635.

[2] C.A. Handwerker in Diffusion Phenomena in Thin Films and Microelectronic Materials, edited by D. Gupta and P.S. Ho (Noyes Publications, Park Ridge, NJ, 1988), pp. 245322.

[3] D. E. Alexander, L.E. Rehn and P.M. Baldo, in Phase Formation and Modification by Beam-Solid Interactions, edited by G.S. Was, L.E. Rehn and D.M. Follstaedt (Materials Research Society, Pittsburgh, PA, 1992), pp. 559-564.

[4] D.E. Alexander, L.E. Rehn, P.M. Baldo and Y. Gao, submitted to Appl. Phys. Lett.

[5] T. C. Chou, C.Y. Wong and K.N. Tu, Appl. Phys. Lett. 49, 1381-1383 (1986).

[6] EMSA Bulletin 17, 94 (1987).

[7] J. D. Pan and R.W. Balluffi, Acta. Metall. 30, 861-870 (1982). 

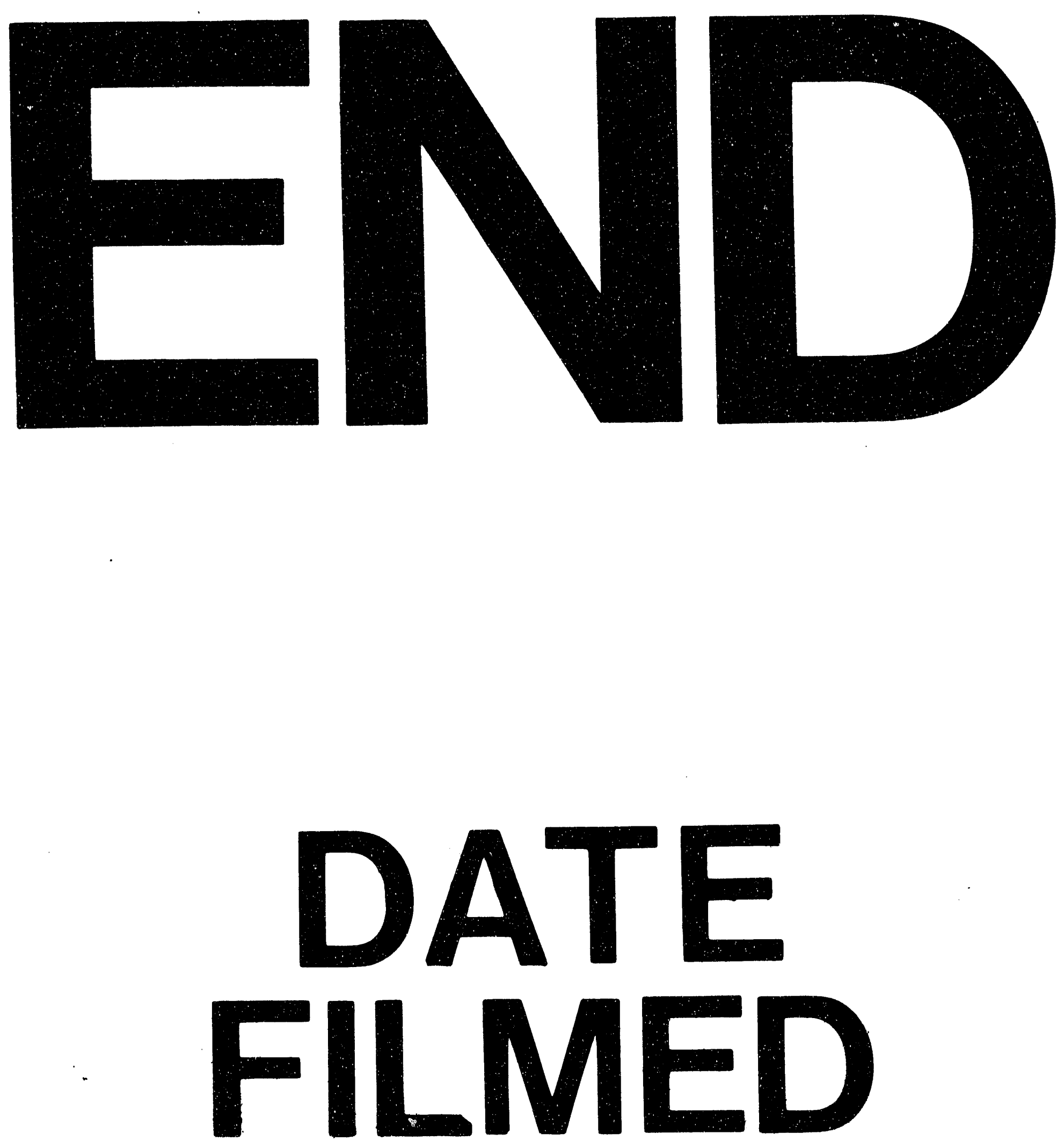

1

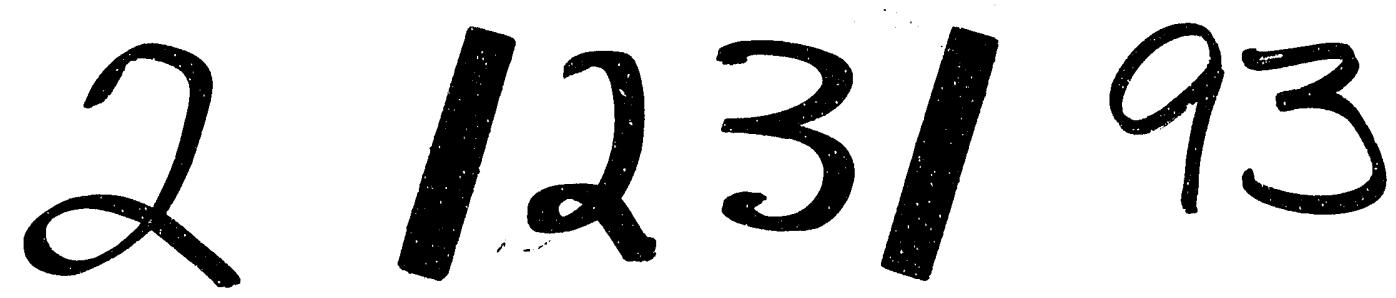


